Revue d'histoire de l'Amérique française

ZRS REVUE D.HISTOIRE DE L'AMÉRIQUE FRANÇAISE

\title{
Les fils de Colons bigourdans de Saint-Domingue, élèves de l'École de Sorèze, au XVIII ${ }^{\mathrm{e}}$ siècle
}

\section{Roger Massio}

Volume 10, numéro 2, septembre 1956

URI : https://id.erudit.org/iderudit/018600ar

DOI : https://doi.org/10.7202/018600ar

Aller au sommaire du numéro

Éditeur(s)

Institut d'histoire de l'Amérique française

ISSN

0035-2357 (imprimé)

1492-1383 (numérique)

Découvrir la revue

Citer cet article

Massio, R. (1956). Les fils de Colons bigourdans de Saint-Domingue, élèves de l'École de Sorèze, au XVIII ${ }^{\mathrm{e}}$ siècle. Revue d'histoire de l'Amérique française, 10(2), 247-249. https://doi.org/10.7202/018600ar d'utilisation que vous pouvez consulter en ligne. 


\section{LES FILS DE COLONS BIGOURDANS DE SAINT-DOMINGUE, ÉLÈVES DE L'ÉCOLE DE SORĖZE, AU XVIII ${ }^{\text {éme }}$ SIÉCLE}

Le clergé fut l'éducateur de la jeunesse au XVIII ${ }^{\text {éme }}$ siècle. Le collège de Sorèze tenu par les Bénédictins était célèbre. Sorèze était devenu en 1776, une des douze écoles militaires reconnues par le ministre de la guerre, alors le comte de Saint Germain. Dom Ferlus en fut à cette époque le directeur le plus célèbre. C'est lui qui créa un enseignement tout moderne sans latin pour un petit nombre de jeunes gens. On comprend que l'éducation des futurs officiers ait inspiré cette modernité de l'enseignement et réservé une très grande place aux exercices du corps, aux exercices militaires, à la gymnastique, à l'équitation, à l'escrime.

La haute bourgeoisie et la bourgeoisie moyenne allaient affluer dans ces collèges où elle coudoyait la noblesse. Elles les fréquentaient à la veille de la Révolution même plus que celle-ci. Comme l'affirme Sagnac ${ }^{1}$ peu avant 1789 , les bourgeois forment les $2 / 3$ de l'effectif. Alors qu'en 1770 sur 220 élèves, il n'y avait que 32 bourgeois, on en compte deux ans après (1772) 77 ; en 1789 , ils constituent les $2 / 3$ de l'effectif qui s'élève à 400 élèves. Le tiers état va naturellement au collège le plus moderne, celui qui aux dépens du latin donne une place aux sciences expérimentales, aux langues étrangères, aux exercices du corps.

Sur la liste des fils de colons de Saint-Domingue à l'École de Sorèze à cette époque sur un total de 175 élèves environ, originaires de la grande ile, on peut compter: 49 nobles et 126 bourgeois. Beaucoup de fils de colons de Saint-Domingue séjourneront à Sorèze, mais ils ne feront pas toujours une scolarité compléte et cela parait lié aux allées et venues des parents de Saint-

1 Ph. Sagnac, La formation de la Société Française moderne (17151788) (Presses Universitaires, 1946) 233-234. - Sur l'Ecole de Sorèze: Abbé Augustin Sicard, Les Etudes Classiques avant la Révolution, 447-493. 
Domingue en France ou de France à Saint-Domingue. Très nombreux sont également les fils de colons en 1794 ; ils semblent avoir été mis à l'abri par les parents en raison des événements dans l'ile à cette date. Mais après 1794 , on rencontre très peu d'élèves venus d'Amérique. C'est que les revenus ont diminué ou même cessé, il n'est plus possible de payer la pension.

La question de l'éducation des enfants était une grave question qui se posait aux colons des îles. D'abord l'éducation et l'instruction à Saint-Domingue n'étaient pas organisées, le nombre des maîtres était insuffisant, seuls quelques membres du clergé, quelques religieuses s'en occupaient, de plus le milieu colonial aux mœurs assez libres n'était pas un exemple pour des enfants. Les parents enfin étaient plus rassurés de savoir leurs enfants en France qu'à la colonie.

L'éducation des enfants de colons ne se faisait pas uniquement dans les collèges des ports, mais presque tous les collèges reçevaient de "jeunes américains »: les collèges des Oratoriens à Niort, à Nantes, ceux de l'ouest, Vendôme, Angers, Thouars, Pontlevoye et Sorèze dans la Montagne Noire. Pontlevoye et Sorèze furent, semble-t-il, les deux collèges a avoir le plus grand nombre de fils de colons.

A Sorèze, nous trouvons trois fils de Bigourdans, colons aux iles: Jean-Laurent de Carrère de Salles fut élève de l'École de Sorèze en 1788-1789. Davezac de Castéra aîné, fut élève de 1777 à 1781, soit pendant quatre ans ; son frère cadet vint l'y rejoindre en 1778 , il y resta six ans jusqu'en 1784 .

Jean-Laurent de Carrère était né au Port-au-Prince, le 27 mars 1778. Sa mère, Élisabeth Dugué, devait mourir l'année suivante à trente quatre ans. Son père François de Carrère meurt en 1784, alors que l'enfant a six ans. Nous ignorons à quelle date le jeune Carrère, orphelin, repasse en France, très certainement après la mort de son père. Il restera quatre ans à SallesAdour et c'est probablement sur les conseils de sa tante Madame de Saint-Sermin de Bagnères-de-Bigorre que l'enfant sera envoyé à Sorèze, à l'âge de dix ans. Il ne passera qu'un an à l'école et les événements révolutionnaires en Bigorre ne sont peut-être pas étrangers à ce bref séjour à l'école. 
Les Davezac de Castéra furent nombreux à Saint-Domingue au XVIII ${ }^{\text {éme }}$ siècle. Les deux Castera qui furent élèves de Sorèze de 1777 à 1784, parâissent être les fils de ce Castera qui fit les grands travaux d'irrigation de la plaine des Cayes. Il devait mourir en 1781. Venu aussi de la plaine des Cayes à Sorèze quelques années auparavant de 1768 à 1773 , se trouvait un Labiche de Reignefort, originaire du Limousin. Les Labiche et les Davezac se connaissaient; un Labiche de Reignefort et un Castera seront arrêtés ensemble en 1793 . Il est possible, les enfants des colons des Cayes étant assez peu nombreux à Sorèze, que Labiche de Reignefort ait incité son voisin à mettre ses fils dans le collège où son fils avait aussi fait une partie de ses études.

Nous ignorerons toujours quelles furent les réactions de ces enfants, de ces petits exilés transplantés des îles à Sorèze et confiés aux pères Bénédictins. Les vertes frondaisons du parc leur rappelaient-elles la végétation des tropiques et les premiers contreforts de la montagne Noire, les mornes étagés auprès de Beauvallon et aussi cette autre Montagne Noire, toute proche de leur habitation? Rien d'autre ne demeure de ce passé que nous aurions voulu saisir, que des noms sur un tableau de l'École, souvenir combien émouvant et que l'histoire se devait de noter.

Roger MASSIO, Vic-Bigorre 